\title{
Discouraging honorific authorship
}

\author{
Olle Persson • Wolfgang Glänzel
}

Received: 29 April 2013

(C) Akadémiai Kiadó, Budapest, Hungary 2013

Scientific collaboration, in general, and team work, in particular, are usually interpreted as characteristics of the era of 'big science' (cf. Price 1963). Above all, the challenges of increasing internationalization and globalization as well as the emergence of new interdisciplinary research fields resulted in an enormous intensification of collaboration. Reasons for collaboration such as 'improving access to funds', 'obtaining prestige or visibility', 'collaboration for professional advancement' (Beaver 2001) imply increasing co-authorship as well. If co-authorship, however, becomes uncoupled from regular scholarly communication processes, mechanisms of funding and professional advancement might indirectly foster strategic co-authorship. Symptoms of the already measurable inflationary tendencies (cf. Persson et al. 2004) are worrying forms of strategic coauthorship such as honorific authorship and hyper-authorship (Cronin 2001). Editors of scientific journals have recognized this phenomenon and began to act on these trends. In January 2010 Bruce Alberts wrote an editorial in Science (Alberts, 2010), where he as editor of Science refers to an agreement with the chief editors of Nature and PNAS to discourage "honorary authorships". For Science the obligation is as follows.

All authors must agree to be so listed and must have seen and approved the manuscript, its content, and its submission to Science. Science will send an email to all authors to confirm receipt of each paper. Submission of a paper that has not been approved by all authors may result in immediate rejection without appeal.

Nature and PNAS have adopted similar instructions to the authors. The expected outcome is that the dramatic increase in the number of authors per article will slow down or end after 2010. When looking at the mean number of authors per article (Fig. 1), it appears that

\footnotetext{
O. Persson

Department Sociol, Umea University, 90187 Umeå, Sweden

e-mail: Olle.Persson@soc.umu.se

W. Glänzel $(\bowtie)$

Centre R\&D Monitoring (ECOOM) and Department of MSI, Katholieke Universiteit Leuven, 3000 Leuven, Belgium e-mail: Wolfgang.glanzel@kuleuven.be
} 


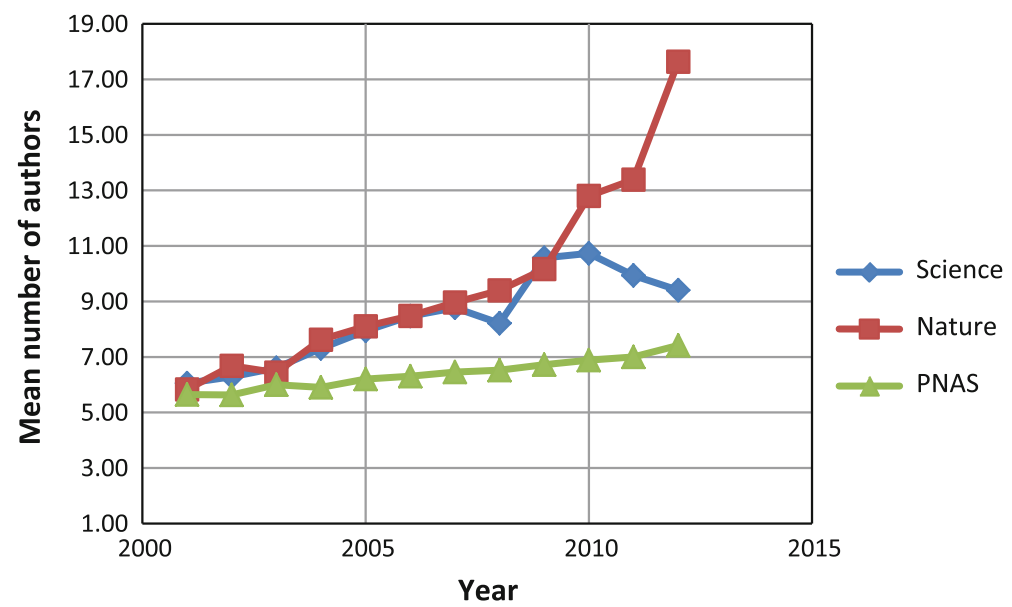

Fig. 1 Mean number of authors per article. Source: Thomson Reuters Web of Science

this policy have been successful for Science but not for Nature and PNAS. Could this be explained by the fact that Science demands each author to respond individually declaring their contribution, while for the other two journals this is done collectively in the manuscript?

If we calculate the median number of authors instead of means, articles with extremely large number of authors do not bias the statistic. Then all three journals give the impression to have complied with the new standard after 2010 (Fig. 2). But what the median value actually tells us, in relation to the mean value, is that Nature and PNAS have been less effective in reducing articles with long lists of authors.

The future will show if the administrative steps taken by the editor-of-chiefs of the above journals will be able yield sustainable results, and, if so, whether the example of Science will be followed by other scientific journals as well.

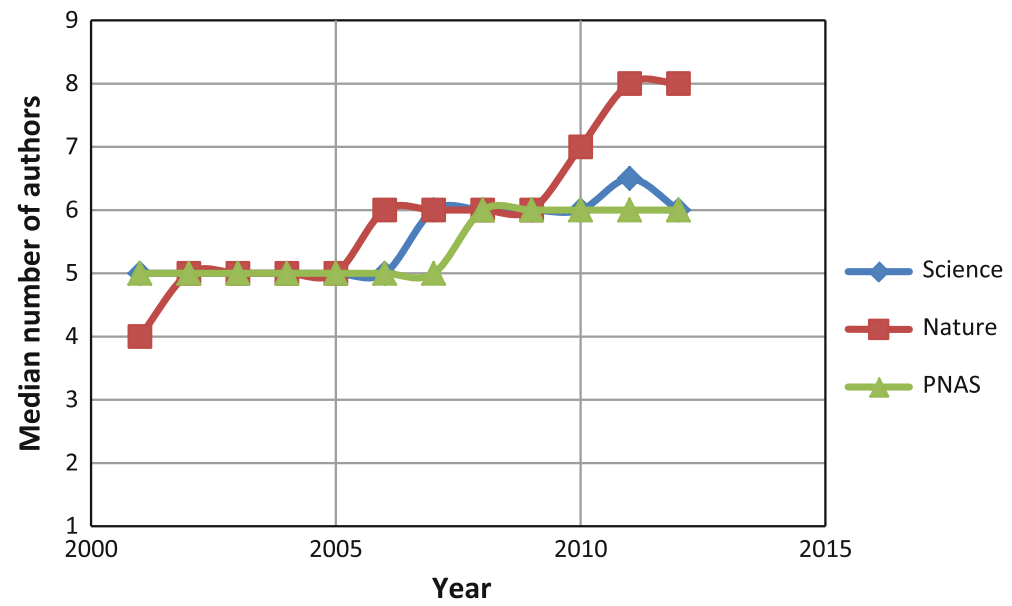

Fig. 2 Median number of authors per article. Source: Thomson Reuters Web of Science 


\section{References}

Alberts, B. (2010). Promoting scientific standards. Science, 327(5961), 12.

Beaver, D. de B. (2001). Reflections on scientific collaborations (and its study): past, present and prospective. Scientometrics, 52, 365-377.

Cronin, B. (2001). Hyperauthorship: a postmodern perversion or evidence of a structural shift in scholarly communication practices? Journal of the American Society for Information Science and Technology, 52(7), 558-569.

Persson, O., Glänzel, W., \& Danell, R. (2004). Inflationary bibliometric values: the role of scientific collaboration and the need for relative indicators in evaluative studies. Scientometrics, 60(3), 421-432.

Price, D. D. (1963). Little Science, Big Science. New York: Columbia University Press. 